\title{
Exploring the influence of maternally derived antibody against hepatitis B surface antigen on infants' immune response to hepatitis $B$ vaccine in mice
}

\author{
Weihong Lv \\ Qingdao Municipal Hospital Group
}

\section{Tao Wei}

Qingdao Women and Childrens Hospital

\section{Shanjuan Tan}

Qingdao Municipal Hospital Group

Ling Li

Qingdao Municipal Hospital Group

\section{Jijun Teng}

Affiliated Hospital of Medical College Qingdao University

Hong Qi

Qingdao Municipal Hospital Group

\section{Tongliang Han}

Qingdao Municipal Hospital Group

Lei Zhang ( $\nabla$ suwen-021@163.com )

Qingdao Municipal Hospital Group https://orcid.org/0000-0003-0793-3789

\section{Research}

Keywords: hepatitis B vaccine, maternal anti-HBs, infant, immune response, BALB/c mice

Posted Date: February 12th, 2020

DOI: https://doi.org/10.21203/rs.2.23401/v1

License: (c) (i) This work is licensed under a Creative Commons Attribution 4.0 International License. Read Full License 


\section{Abstract}

Background: Whether maternal anti-HBs acquired transplacentally plays a negative role in newborn infants' immune response to hepatitis B vaccine (HepB Vac), it remains controversial and has not been paid enough attention.

Methods: 267 BALB/c mice were bred. All mice were divided into two groups according to different doses of HepB Vac $(2 \mu \mathrm{g}, 5 \mu \mathrm{g})$ injected to mice. Each group was sub-divided into three subgroups according to different doses of hepatitis B immunoglobulin (HBIG) (50 IU, 25 IU, 0 IU) injected combined with the first dose of HepB Vac. Three doses of HepB Vac were administrated at 0 week, 4week and 8 week respectively. Antibodies against hepatitis $B$ surface antigen (anti-HBs) were tested four weeks after the third dose of HepB Vac.

Results: Among 267 mice, 40 were of low- and non-response to HepB Vac (anti-HBs $<100 \mathrm{mlU} / \mathrm{mL}$ ). Multivariate logistic regression analysis showed that rates of anti-HBs $<100 \mathrm{mlU} / \mathrm{mL}$ were: $1.1 \%, 23.1 \%$ and $20.7 \%$ in groups of $\mathrm{HBIG}=0 \mathrm{IU}(1), \mathrm{HBIG}=25 \mathrm{IU}(2)$ and $\mathrm{HBIG}=50 \mathrm{IU}(3)$ respectively, $\mathrm{p}=0.002$, and among subgroups, (1) vs (3), RR= $0.032,95 \% \mathrm{Cl}[0.004,0.255], \mathrm{p}=0.001,(2)$ vs (3), RR=1.359, $95 \% \mathrm{Cl}$ $[0.588,3.144], p=0.473 ; 4.5 \%$ and $25.6 \%$ in groups of HepB Vac $5 \mu \mathrm{g}$ and $2 \mu \mathrm{g}, \mathrm{RR}=0.093,95 \% \mathrm{Cl}[0.035$, $0.250], p<0.001 ; 6.1 \%$ and $23.7 \%$ in groups of intramuscular injection and hypodermic injection, $\mathrm{RR}=0.139,95 \% \mathrm{Cl}[0.056,0.346], \mathrm{p}<0.001$. The mean titers of anti-HBs $(\log 10 \mathrm{mlU} / \mathrm{m})$ were on the decrease in turn in groups of $\mathrm{HBIG}=0 \mathrm{IU}, \mathrm{HBIG}=25 \mathrm{IU}$ and $\mathrm{HBIG}=50 \mathrm{IU}, \mathrm{p}<0.001$.

Conclusions: HBIG has a negative impact on both the rate of effective immune response and response level of anti-HBs, which preliminarily indicates maternal anti-HBs inhibits infants' immune response to HepB Vac.

\section{Background}

Hepatitis B virus (HBV) infection is a serious global health problem[1]. Infants and young children who become infected with HBV are the most likely to develop chronic infection [2,3]. Routine immunization of hepatitis B vaccine (HepB Vac) before the age of one year is the most cost-effective prevention and control strategy for hepatitis B transmission. In China, the infection of HBV is one of the major obstacles to public health, and a dramatic reduction of HBV transmission has reached since HepB Vac has been integrated into the national expanded program on immunization in 1992[4].

A new phenomenon has appeared that more and more child-bearing age women (around 56-59\%) are positive for anti-HBs as a result of the effective immunoprophylaxis of HBV and pregnant women with higher anti-HBs titer ( $\geq 500 \mathrm{IU} / \mathrm{L}$ ) accounted for $21 \%[5,6]$. Predictably, a certain amount of anti-HBs will be found in growing number of neonates at birth at the base of the fact that maternal anti-HBs which virtually is IgG antibodies transplacentally transported to fetus actively[7]. It is reasonable to speculate that the efficacy of vaccination, related to the effectiveness and persistence of immunity, which routinely conducted at 0-1-6 months after birth could be diminished by maternal anti-HBs. 
Infants are still vulnerable to be infected with HBV if they do not obtain adequate anti-HBs which is negative or considers as low-response after a complete course of immunization [8]. Although significant progress has made in hepatitis $B$ control in China, but challenges remain. Among young people, the HBsAg prevalence was higher in teenagers 5-14 years than in children 1-4 years, which might be related to the low or negative response to the primary HBV vaccination[4]. Therefore it is important for improving the status of hepatitis B control to make sure that infants obtain adequate anti-HBs after vaccination.

However, the study in neonates poses special ethical challenges because of the great vulnerability of this population. There are some difficulties when blood of umbilical cord or vein blood from newborns right after birth as well as vein blood after the complete course of vaccination are collected in China. Two key factors that affect sample collection are: i few mothers consent to have their babies pricked to yield a blood sampled; ii Neonates scatter from the birth hospital where a timely birth dose of HepB Vac is administrated to different community hospitals where the subsequent two doses are administrated, which make it difficult to follow up the infants after vaccination. We design a primary study to access if maternal anti-HBs inhibit the immune response of HepB Vac in BABL/c mice which are generally used for immunological study $[9,10]$.

\section{Methods}

\section{Experimental animals}

From January 2016 to July 2018, 267 BALB/c mice (139 male and 128 female) of SPF grade aged three to eight weeks, with median ( $25 \%$ to $75 \%$, interquartile range, IQR) age of $6(4,8)$ weeks, were bred, among whom 136 were housed at animal experiment center of affiliated hospital of Qingdao university in 2016 and 131 were housed at animal experiment center of medical college of Qingdao university, among whom 60 were raised in 2017 and 71 in 2018. All mice were allowed to acclimate the environment within the first week at the beginning of the study and all of them had standard feedstuff and drank purified water freely. The mice were exposed to a 12 hour light -12 hour dark cycle at $22 \pm 2{ }^{\circ} \mathrm{C}$ with relative humidity of $60 \% \pm 5 \%$. All mice were recorded sex, age, dose of HepB Vac, dose of hepatitis $B$ immunoglobulin (HBIG), vaccination route and vaccination schedule before the first immunization. The mice and standard feedstuff were purchased from Qingdao Daren Fucheng Graziery co. LTD in China.

\section{Materials and methods}

\section{प Reagents}

Recombinant Hepatitis B Vaccine (Hansenula Polymorpha): specification, 10 $\mu \mathrm{g} / 0.5 \mathrm{ml}$, approval number: S20040016, produced by Dalian Hanxin Biological Pharmaceutical Co., LTD in China.

HBIG: specification, 200 IU/2ml, approval number: S10930001, produced by Shandong Taibang Biological Products Co., LTD in China. 
ARCHITECT Anti-HBs Reagent Kit: produced by Abbott Ireland Diagnostics Division.

\section{Q Laboratory methods}

Anti-HBs were performed by a chemiluminescence microparticle immunoassay using ARCHITECT i 2000 full-automatic immune analysis system. The normal reference value was set as $0-10 \mathrm{mlU} / \mathrm{mL}$. One test was carried out for each sample.

For the specimens of anti-HBs titer $\otimes 1000 \mathrm{mlU} / \mathrm{mL}$, they were diluted to 10 times, 20 times or 30 times, and so on, until anti-HBs levels fell below the upper limit of detection $(1000 \mathrm{mlU} / \mathrm{mL})$.

\section{Grouping and Immunization Schedule}

\section{प Grouping}

All the mice were divided into two groups (group A and group B) according to the different doses of HepB Vac injected to mice. Group $A$ was sub-divided into three subgroups: A1, A2, A3; and group B was subdivided into three subgroups: B1, B2, B3.

\section{$\square$ Number and injection routes of each group}

Each group included at least 40 mice: around 20 males and 20 females. HepB Vac was injected through two routes: intramuscular injection (quadriceps femoris, at least 10 males and 10 females) and hypodermic injection (scruff, at least 10 males and 10 females). HBIG was administrated through intraperitoneal injection.

\section{Q Immunization schedule}

The time when the experiment was started was defined as 0 week $(w)$, the next as $1 w$, and so on.

Subgroups A1, A2, A3

A1: 25 IU HBIG and $2 \mu \mathrm{g} \mathrm{HepB} \mathrm{Vac} \mathrm{were} \mathrm{administrated} \mathrm{at} 0 \mathrm{w}$, and then the second and third HepB Vac of the same dose were administrated at $4 \mathrm{w}$ and $8 \mathrm{w}$ respectively.

A2: 50 IU HBIG and $2 \mu \mathrm{g} \mathrm{HepB} \mathrm{Vac} \mathrm{were} \mathrm{administrated} \mathrm{at} 0$ w, and then the second and third HepB Vac of the same dose were administrated at $4 \mathrm{w}$ and $8 \mathrm{w}$ respectively.

A3: Three doses HepB Vac of $2 \mu \mathrm{g}$ were administrated at $0 \mathrm{w}, 4 \mathrm{w}$ and $8 \mathrm{w}(0-4-8 \mathrm{w})$ respectively.

Subgroups B1, B2, B3

B1: 25 IU HBIG and 5 $\mu$ g HepB Vac were administrated at 0 w, and then the second and third HepB Vac of the same dose were administrated at $4 \mathrm{w}$ and $8 \mathrm{w}$ respectively. 
B2: 50 IU HBIG and $5 \mu \mathrm{g} \mathrm{HepB} \mathrm{Vac} \mathrm{were} \mathrm{administrated} \mathrm{at} 0$ w, and then the second and third HepB Vac of the same dose were administrated at $4 \mathrm{w}$ and $8 \mathrm{w}$ respectively.

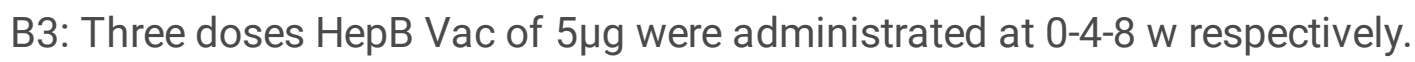

\section{Definition of immunization outcome}

Anti-HBs $₫ 10 \mathrm{mIU} / \mathrm{mL}$ was considered as non-response; anti-HBs from 10 to $100 \mathrm{mlU} / \mathrm{mL}$ was considered as low-response; anti-HBs $>100 \mathrm{mIU} / \mathrm{mL}$ was considered as protective response; anti-HBs $>1000 \mathrm{mlU} / \mathrm{mL}$ was considered as high-response[8, 11].

\section{Sample collection in mice}

Four weeks after the third dose of HepB Vac, blood was collected from the mice eye socket by vacuum tubes (no additives) [12]. The mice were sacrificed immediately after the blood was drawn. The serum were separated within one hour, transferred into 1.5 centrifuge tube and stored in a $-70{ }^{\circ} \mathrm{C}$ for anti-HBs testing.

\section{Statistical analysis}

$x^{2}$ or fisher's exact tests were used for categorical variables. For measurement data, normal distribution was first tested. If the result was of non-normal distribution, it was expressed in terms of median ( $25 \%$ to $75 \%$ interquartile range, IQR). The result of anti-HBs titer in this study did not obey normal distribution, and it presented normal distribution after taking logarithm. Thus the measurement data was analyzed by means of logarithms and $t$ test or analysis of variance was used, expressed asx $\pm S D$. Logistic regression analysis was used to identify the risk factors. Variables assignments are as follows: Sex, Female $=0$, Male=1; HBIG dose, $0 \mathrm{IU}=0,25 \mathrm{IU}=1,50 \mathrm{IU}=2$; HepB Vac dose, $2 \mu \mathrm{g}=0,5 \mu \mathrm{g}=1$; Route of HepB Vac injection, hypodermic $=0$, intramuscular=1. And categorical variables (HBIG 0 IU, $25 \mathrm{IU}, 50 \mathrm{IU})$ were transformed into dummy variables [(1), (2), (3)]. Variables with $p$ value $<0.1$ in the univariate analysis were included in a multivariate logistic regression. Statisticalcal culations were performed using SPSS 22.0 software package with a $p$ value $<0.05$ considered significantly.

\section{Results}

\section{The profile of immune response among mice}

A total of 267 mice have completed the whole immunization schedule, and the number of each subgroup is in the range of 41 to 48 . Among all the mice, 40 (14.98\%) were of low- and non-response to HepB Vac (anti-HBs $₫ 100 \mathrm{mIU} / \mathrm{mL}$ ), among whom 10 (3.75\%) were of non-response to HepB Vac (anti-HBs $\unrhd 10$

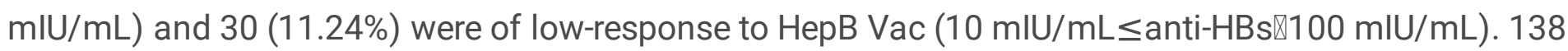
(51.69\%) were of high-response to HepB Vac (anti-HBs>1000 mlU/mL). 89 (33.33\%) were between the above two groups $(100 \mathrm{mlU} / \mathrm{mL} \leq$ anti-HBs $₫ 1000 \mathrm{mlU} / \mathrm{mL})$. As regard to the samples with anti-HBs $>1000$ $\mathrm{mIU} / \mathrm{mL}$, the specific anti-HBs levels were obtained in a range from $10^{3}-10^{6} \log _{10} \mathrm{mlU} / \mathrm{mL}$ after dilution. 


\section{Risk factors for low- and non-response to HepB Vac among mice}

Among the 267 mice of 0-4-8 w schedule, the rate of low- and non-response to HepB Vac was significantly higher in the group with HBIG than group without HBIG; that was significantly higher in the group of $2 \mu \mathrm{g} \mathrm{HepB} \mathrm{Vac} \mathrm{than} \mathrm{group} \mathrm{of} 5 \mu \mathrm{g} \mathrm{HepB} \mathrm{Vac;} \mathrm{and} \mathrm{that} \mathrm{was} \mathrm{also} \mathrm{significantly} \mathrm{higher} \mathrm{in} \mathrm{the} \mathrm{group}$ of hypodermic injection than group of intramuscular injection. Multivariate logistic regression analysis showed that HBIG, lower dose of HepB Vac and hypodermic injection were the independent risk factors for low- and non-response to HepB Vac among mice, as shown in Table 1.

\section{The effect of HBIG of different doses on anti-HBs levels in mice vaccinated}

The effect of HBIG doses on anti-HBs levels was analyzed among the mice adopted intramuscular injection in 0-4-8 w schedule. We just selected the mice in that group because intramuscular injection is the route most commonly used in clinical settings. Among the three groups of different HBIG doses $₫$ the mean anti-HBs titers decreased gradually from HBIG 0 IU group to HBIG 50 IU group, and the differences were statistically significant. That showed the same trend in both HepB Vac $2 \mu \mathrm{g}$ group and HepB Vac $5 \mu$ group. There was also significant difference in each pairwise comparison except for the comparison between $B$ and $C(p \otimes 0.05)$. The above are shown in Table 2.

\section{Factors related to high-response to HepB Vac among mice}

Among the 267 mice of 0-4-8 w schedule, the rate of high-response to HepB Vac was significantly higher in the group without HBIG than group with HBIG; that was significantly higher in the group of $5 \mu \mathrm{g} \mathrm{HepB}$ Vac than group of $2 \mu \mathrm{g} \mathrm{HepB} \mathrm{Vac;} \mathrm{and} \mathrm{that} \mathrm{was} \mathrm{also} \mathrm{significantly} \mathrm{higher} \mathrm{in} \mathrm{the} \mathrm{group} \mathrm{of} \mathrm{intramuscular}$ injection than group of hypodermic injection. Multivariate logistic regression analysis showed that without HBIG, higher dose of HepB Vac and intramuscular injection were the independent factors related to high-response to HepB Vac among mice, as shown in Table 3.

\section{Discussion}

In recent years, some experts have already noticed that maternal antibodies influence infant vaccine responses for almost all vaccines contained in global immunization programs, however, owing to the small size of most studies, there is inconsistent evidence on the extent of this inhibition and a lack of consensus regarding which antigens or vaccines are affected[13, 14]. Our viewpoint about maternal antiHBs influences infant HepB Vac response is similar to the above experts' opinions, and this study is designed in order to highlights the potential to influence the established HepB Vac immunization programs.

For the first time, we simulated the fact that neonates got anti-HBs from their mothers by injection of $\mathrm{HBIG}$ to $\mathrm{BABL} / \mathrm{c}$ mice based on the fact that HBIG which is derived from plasma donated by individuals immune to hepatitis $B$ viral infection is a purified solution of human immunoglobulin that has high titers of anti-HBs[15]. And then three separate doses of HepB Vac were given to each mouse at 0-4-8 $w$. In this 
study, 0-4-8 w schedule was taken mainly because the lifespan of mice is short and four weeks are an appropriate time interval recommended in the literature[16]. The effectiveness of vaccination was evaluated in order to ascertain whether maternal anti-HBs affected the immune response of HepB Vac routinely given at 0-1-6 months.

The findings obtained from our previous study showed that anti-HBs positive rate in cord blood (placental pass rate) was $94.2 \%$ with median titers lightly higher than their mothers', and another set of data from our study showed that anti-HBs positive rate and median titer were both lower in infants from the higher maternal titer group after the completion of the three-step vaccination[5].That indicated that high maternal titer of anti-HBs (transplacental transferred) influenced infants' immune response to the HBV vaccine. However, the two sets of data was studied in two different groups, so the findings cannot provide direct evidence that transplacental maternal anti-HBs impairs infants' immune response to HepB Vac. Unfortunately, the data about anti-HBs from the same group of a large sample size before and after the primary vaccination has not been reported yet at present.

The main results (Table 1,2) in this study were consistent with previous findings in infants followed up after a full vaccine scheme [5]. It provided the evidence about the speculation that infants' active immune response was suppressed by transplacental anti-HBs from their mothers in HBV vaccination. Similarly, Hu et al[17] have suggested that the immune response in infants with high concentrations of maternal anti$\mathrm{HBs}(>1000 \mathrm{mlU} / \mathrm{mL}$ ) was significantly lower after the third injection. Regarding immunoprophylaxis against vertical HBV transmission, some authors have reported lower anti-HBs titers in newborn infants receiving HBIG plus HBV vaccine at birth than in newborn infants receiving the $\mathrm{HBV}$ vaccine only[18, 19]. It indicated that HBIG can neutralize HepB Vac while it provides passive immunization for infants who could be exposed to HBV. But, in contrast, some studies did not find an association between the level of maternal anti-HBs and HepB Vac response in the neonates [20,21]. By comparison, it showed that the drop out rate was very high in the cohort studies, doses of HepB Vac used were different, and some data from retrospective survey was not continuous[17, 20,21], which could be the reason of getting the negative results in those studies. Future studies should enroll a large number of subjects to fully clarify the influence of maternal anti-HBs on the active immune response to HepB Vac.

In this study, we found that anti-HBs titer were at the level of $10^{3}-10^{6} \log _{10} \mathrm{mlU} / \mathrm{mL}$ when samples with anti-HBs $₫ 1000 \mathrm{mlU} / \mathrm{mL}$ were completed the dilution. Because long term persistence of anti-HBs protector titer have been related to higher anti-HBs titer peaks after a full vaccine scheme[22, 23], those samples

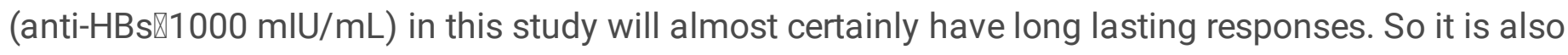
suggested that maternal anti-HBs could be one of factors affecting persistent immune response.

Results in this study suggested that the lower dose of vaccine was the independent risk factors resulted in low- and non-response of immunity (Table 1), and the higher dose of vaccine was the independent factor that help to produce high immune response (Table 3), which indicated that administration of a higher dose of vaccine could lead to a better immune response. Thus, we could speculate that a higher dose of HepB Vac was sufficient to compensate the binding of maternal anti-HBs to HepB Vac, and 
adequately challenging the infants' immune systems and consequently eliciting high anti-HBs titers. From the studies conducted by Hu[17] and Junqueira[21](10 $\mu \mathrm{g}$ vs $5 \mu \mathrm{g})$, we can draw the similar conclusion to the opinion got above.

The correct vaccination route can achieves higher effect of immune response. By comparison of administration routes, results showed the intramuscular injection could achieve higher effect than the hypodermic injection both in effective response rate and in high response rate. In China, HepB Vac is universally administrated through intramuscular injection, which is consistent with the practice recommend by $\mathrm{WHO}[16]$.Since intramuscular injection, hypodermic injection and intraperitoneal injection are the common routes for vaccines administration in mice, and the results may provide evidence that muscle injection is the priority way for the hepatitis $B$ vaccination in mice.

According to the main results of the study, we propose the suggestion that it should be taken different strategies for hepatitis B vaccination to newborns according to the pattern of hepatitis B virus markers of their mothers which is universally tested during pregnancy in China. For infants born to HBsAg positive mothers, timely delivery of the first dose of vaccine combined with HBIG (within 24 hours of birth) should be given to them as a safe guard to preventing perinatal transmission of HBV. And for infants born to HBsAg negative mothers, they are largely protected by the presence of maternal antibody in the early perinatal period, so it is suggested that the first dose of HepB Vac is postponed to avoid the interference of maternal anti-HBs.

As to the specific first dose time, it needs further study. It is reported that the level of maternally derived antibody declined rapidly over the first four weeks of life and then more slowly[24], and passively derived HBIG can be detected for 4-6 months[25], so the appropriate delayed time might be considered to be between one month age and six month age or within one year of birth. In addition, older infants generally respond better to vaccines while infant immune competence gradually increases[26]. Agladioglu $S$ et al. [27] suggested that delaying the first dose of the HepB Vac until 2 months after birth, 2-4-9 (age in months) schedule to infants of HBsAg-negative mothers produces a higher immune response and can provide longer term protection, whose opinion is consistent with our speculation. As there was with the measles vaccine which was ultimately made the decision to vaccinate children at the age of eight months to avoid the impact by the level of maternal antibody to measles virus in China, greater understanding of the effect of maternal anti-HBs on immune response of HepB Vac will help national policy makers to determine the appropriate age for hepatitis $B$ vaccination[28].

Although, from the perspective of theory, it is possible to take a different strategy of the first dose HepB vaccine according to maternal HBsAg status, it seems not practical for routine vaccination currently. On one hand, showing the result of maternal anti-HBs quantitative value is not compulsory when HepB vaccine is administered to an infant; on the other hand, it is more important to administrate timely and early immunization to infants to minimize the post- exposure transmission than to delay the first dose in infants to obtain a better immune efficacy in endemic area before the elimination of HBV. However, higher final antibody levels are associated with longer persistence of protective anti-HBs, so it still can't be 
ignored the possibility that transplacental anti-HBs may inhibit the active immune effect of HepB Vac among newborns. The best way to address this problem maybe to take timely anti-HBs testing after primary immunization, and individuals whose anti-HBs do not meet the protective level are recommended to revaccinate the HepB Vac.

The limitation of the study is that the administration of HBIG is proposed to mimic the trasplacentally obtained maternal anti-HBs. It was feasible but the process of transplacental transmission of anti-HBs throughout pregnancy is not included in the model. A new group of mice might be set up, injected HepB vaccine, let them breed and then checked the antibody of offspring after three doses of HepB vaccines compared with the antibody response of group of mother mice without HepB vaccination. Moreover, further studies are needed to optimize the conditions (i.e. HepB Vac dose, HBIG dose, injection schedule, and mice weight) that would help to refine the results.

In conclusion, a dramatic reduction of HBV infection rate has reached because of universal immunization in China, and it should be of great importance to pay a close attention to the problem whether maternal anti-HBs interfere with the active immune response to HepB Vac. That is an urgent public health problem to solve in the process of "eliminating viral hepatitis" which is the global target adopted by WHO in 2016. In the long term, research may need to be done in clinical settings if results of further studies in mice are highly suggested maternal anti-HBs can inhibit infants' immune response to HepB Vac.

\section{Abbreviations}

HepB Vac, hepatitis B vaccine; HBIG, hepatitis B immunoglobulin; HBV, Hepatitis B virus; anti-HBs, antibody against hepatitis B surface antigen; WHO, World Health Organization.

\section{Declarations}

\section{Ethics approval and consent to participate}

The study complies with the revised Animals (Scientific Procedures) Act 1986 in the UK and Directive 2010/63/EU in Europe. It was approved by the Ethics Committee of Qingdao Municipal Hospital affiliated with Qingdao University. Animals' care was in accordance with institutional guidelines.

\section{Consent for publication}

Not applicable.

\section{Availability of data and materials}

All datasets on which the conclusions of the manuscript rely will be shared upon request.

\section{Competing interests}


The authors declare that they have no conflict of interest.

\section{Funding}

This work was supported by National Nature Science Foundation of China [grant number 81502900 ]. The funder had no role in the study design, data collection and analysis, decision to publish or manuscript preparation.

\section{Authors' contributions}

LZ, WL and TW conceived the study. LZ, WL, TW, LL, ST, JT, HQ and TH designed the study. All authors acquired and analysed the data. All authors interpreted the findings. LZ wrote the first draft of the manuscript. WL, TW, LL, ST, JT, HQ and TH drafted subsequent versions. All authors critically reviewed this report and approved the final version.

\section{Acknowledgments}

We express our sincere appreciations to Professor Xi'en Gui from Zhongnan Hospital of Wuhan University for his assistance in preparation of this article.

\section{Authors' Information}

${ }^{1}$ Department of Infection Control, Qingdao Municipal Hospital, No.5 donghai middle road, shinan district, Qingdao, Shandong Province, China. ${ }^{2}$ Qingdao Women and Children's Hospital, No. 6 tongfu road, shibei district, Qingdao, Shandong Province, China. ${ }^{3}$ Affiliated Hospital of Qingdao University, No. 1677 wutaishan road, huangdao development zone, Qingdao, Shandong Province, China. ${ }^{4}$ Department of General Surgical, Qingdao Municipal Hospital, No.5 donghai middle road, shinan district, Qingdao, Shandong Province, China. ${ }^{5}$ Department of Ultrasound, Qingdao Municipal Hospital, No.5 donghai middle road, shinan district, Qingdao, Shandong Province, China.

\section{References}

1. Hepatitis B vaccines prepared from yeast by recombinant DNA techniques: memorandum from a WHO meeting. Bulletin of the World Health Organization. 1985; 63(1):57-61.

2. Hyams KC. Risks of chronicity following acute hepatitis B virus infection: a review. Clinical infectious diseases : an official publication of the Infectious Diseases Society of America. 1995; 20(4):9921000.

3. Mast EE, Margolis HS, Fiore AE, Brink EW, Goldstein ST, Wang SA, et al. A comprehensive immunization strategy to eliminate transmission of hepatitis B virus infection in the United States: recommendations of the Advisory Committee on Immunization Practices (ACIP) part 1: immunization of infants, children, and adolescents. MMWR Recommendations and reports : Morbidity and mortality weekly report Recommendations and reports. 2005; 54(Rr-16):1-31. 
4. Liang X, Bi S, Yang W, Wang L, Cui G, Cui F, et al. Reprint of: Epidemiological serosurvey of Hepatitis B in China-declining HBV prevalence due to Hepatitis B vaccination. Vaccine. 2013; 31 Suppl 9:J218.

5. Zhang L, Gui XE, Teter C, Zhong H, Pang Z, Ding L, et al. Effects of hepatitis B immunization on prevention of mother-to-infant transmission of hepatitis $B$ virus and on the immune response of infants towards hepatitis B vaccine. Vaccine. 2014; 32(46):6091-7.

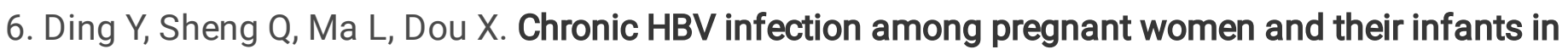
Shenyang, China. Virol J. 2013; 10:17.

7. Roopenian DC, Akilesh S. FcRn: the neonatal Fc receptor comes of age. Nat Rev Immunol. 2007; 7(9):715-25.

8. Wang C, Wang C, Jia ZF, Wu X, Wen SM, Kong F, et al. Protective effect of an improved immunization practice of mother-to-infant transmission of hepatitis $B$ virus and risk factors associated with immunoprophylaxis failure. Medicine. 2016; 95(34):e4390.

9. Marsac D, Puaux AL, Riviere $Y$, Michel ML. In vivo induction of cellular and humoral immune responses by hybrid DNA vectors encoding simian/human immunodeficiency virus/hepatitis $B$ surface antigen virus particles in BALB/c and HLA-A2-transgenic mice. Immunobiology. 2005; 210(5):305-19.

10. Devasahayam M. Factors affecting the presentation of exogenous hepatitis $B$ virus core antigen. Indian journal of experimental biology. 2007; 45(8):689-95.

11. Lu IC, Jean MC, Lin CW, Chen WH, Perng DS, Lin CW, et al. Predictive factors for anti-HBs status after 1 booster dose of hepatitis B vaccine. Medicine. 2016; 95(39):e5023.

12. Parasuraman $S$, Raveendran $R$, Kesavan R. Blood sample collection in small laboratory animals. Journal of pharmacology \& pharmacotherapeutics. 2010; 1(2):87-93.

13. Voysey M, Kelly DF, Fanshawe TR, Sadarangani M, O'Brien KL, Perera R, et al. The Influence of Maternally Derived Antibody and Infant Age at Vaccination on Infant Vaccine Responses : An Individual Participant Meta-analysis. JAMA pediatrics. 2017; 171(7):637-46.

14. Zimmermann P, Curtis N. Factors That Influence the Immune Response to Vaccination. Clinical microbiology reviews. 2019; 32(2).

15. Habib S, Shaikh OS. Hepatitis B immune globulin. Drugs Today (Barc). 2007;43(6):379-94.

16. Hepatitis B vaccines. Wkly Epidemiol Rec. 2009; 84(40):405-19.

17. Hu Y, Wu Q, Xu B, Zhou Z, Wang Z, Zhou YH. Influence of maternal antibody against hepatitis B surface antigen on active immune response to hepatitis $B$ vaccine in infants. Vaccine. 2008; 26(48):6064-7.

18. Yang YJ, Liu CC, Chen TJ, Lee MF, Chen SH, Shih HH, et al. Role of hepatitis B immunoglobulin in infants born to hepatitis B e antigen-negative carrier mothers in Taiwan. The Pediatric infectious disease journal. 2003; 22(7):584-8. 
19. Pongpipat $D$, Suvatte $V$, Assateerawatts $A$. Hepatitis $B$ immunization in high risk neonates born from HBsAg positive mothers: comparison between plasma derived and recombinant DNA vaccine. Asian Pacific journal of allergy and immunology. 1989; 7(1):37-40.

20. Wang Z, Zhang S, Luo C, Wu Q, Liu Q, Zhou YH, et al. Transplacentally acquired maternal antibody against hepatitis $B$ surface antigen in infants and its influence on the response to hepatitis $B$ vaccine. PLoS One. 2011; 6(9):e25130.

21. Junqueira AL, Tavares VR, Martins RM, Frauzino KV, Silva AM, Rodrigues IM, et al. Presence of maternal anti-HBs antibodies does not influence hepatitis $B$ vaccine response in Brazilian neonates. Mem Inst Oswaldo Cruz. 2011; 106(1):113-6.

22. Duval B, Gilca V, Boulianne N, De Wals P, Masse R, Trudeau G, et al. Comparative long term immunogenicity of two recombinant hepatitis $B$ vaccines and the effect of a booster dose given after five years in a low endemicity country. The Pediatric infectious disease journal. 2005; 24(3):213-8.

23. Wu JS, Hwang LY, Goodman KJ, Beasley RP. Hepatitis B vaccination in high-risk infants: 10-year follow-up. J Infect Dis .1999; 179(6):1319-25.

24. Weeratna RD, Brazolot Millan CL, McCluskie MJ, Siegrist CA, Davis HL. Priming of immune responses to hepatitis B surface antigen in young mice immunized in the presence of maternally derived antibodies. FEMS immunology and medical microbiology. 2001; 30(3):241-7.

25. Schillie S, Murphy TV, Sawyer M, Ly K, Hughes E, Jiles R,et al. CDC guidance for evaluating healthcare personnel for hepatitis $\mathrm{B}$ virus protection and for administering postexposure management. MMWR Recommendations and reports : Morbidity and mortality weekly report Recommendations and reports. 2013; 62(Rr-10):1-19.

26. Siegrist CA. Neonatal and early life vaccinology. Vaccine. 2001; 19(25-26):3331-46.

27. Agladioglu S, Beyazova U, Camurdan AD, Sahin F, Atak A. Immunogenicity of recombinant hepatitis B vaccine: comparison of two different vaccination schedules. Infection. 2010; 38(4):269-73.

28. Zheng J, Zhou Y, Wang H, Liang $X$. The role of the China Experts Advisory Committee on Immunization Program. Vaccine. 2010; 28 Suppl 1:A84-7.

\section{Tables}

Table 1. Risk factors of low- and non-response to HepB Vac among mice 


\begin{tabular}{|c|c|c|c|c|c|c|}
\hline \multirow[t]{2}{*}{ Item } & \multirow[t]{2}{*}{$\mathrm{n}$} & \multirow{2}{*}{$\frac{\text { anti-HBs }<100 \mathrm{mIU} / \mathrm{mL}}{\mathrm{n}(\%)}$} & \multicolumn{2}{|c|}{ Univariate analysis } & \multicolumn{2}{|c|}{ Multivariate analysis } \\
\hline & & & $\mathrm{RR}$ value $(95 \% \mathrm{CI})$ & $p$ value & RR value $(95 \% \mathrm{CI})$ & $p$ value \\
\hline Sex & & & $1.149(0.585,2.257)$ & 0.687 & & \\
\hline Male & 139 & $22(15.8)$ & & & & \\
\hline Female & 128 & $18(14.1)$ & & & & \\
\hline HBIG dose & & & & 0.007 & & 0.002 \\
\hline $0 \mathrm{IU}(1)$ & 89 & $1(1.1)$ & $0.044(0.006,0.334)$ & 0.003 & $0.032(0.004,0.255)$ & 0.001 \\
\hline $25 \mathrm{IU}(2)$ & 91 & $21(23.1)$ & $1.150(0.564,2.344)$ & 0.700 & $1.359(0.588,3.144)$ & 0.473 \\
\hline 50 IU (3) & 87 & $18(20.7)$ & & & & \\
\hline HepB Vac dose & & & $0.136(0.055,0.338)$ & $<0.001$ & $0.093(0.035,0.250)$ & $<0.001$ \\
\hline $5 \mu \mathrm{g}$ & 134 & $6(4.5)$ & & & & \\
\hline $2 \mu \mathrm{g}$ & 133 & $34(25.6)$ & & & & \\
\hline Route of HepB Vac injection & & & $0.208(0.092,0.470)$ & $<0.001$ & $0.139(0.056,0.346)$ & $\leq 0.001$ \\
\hline intramuscular & 132 & $8(6.1)$ & & & & \\
\hline hypodermic & 135 & $32(23.7)$ & & & & \\
\hline
\end{tabular}

Table 2. Effect of HBIG doses on anti-HBs levels in mice vaccinated

\begin{tabular}{|c|c|c|c|c|c|c|}
\hline & \multirow[t]{2}{*}{ Group } & \multicolumn{3}{|c|}{ HBIG dose凹IU } & \multirow[t]{2}{*}{ F value } & \multirow[t]{2}{*}{$p$ value } \\
\hline & & 0 & 25 & 50 & & \\
\hline \multirow[t]{2}{*}{ HepB Vac $5 \mu \mathrm{g}$} & $\mathrm{n}$ & 21 & 24 & 21 & & \\
\hline & anti-HBs titer $($ 园 $\pm S D)$ & $5.09 \pm 0.36(\mathrm{~A})$ & $4.29 \pm 1.07(\mathrm{~B})$ & $3.97 \pm 1.02(\mathrm{C})$ & 8.889 & $<0.001$ \\
\hline \multirow[t]{2}{*}{ HepB Vac $2 \mu \mathrm{g}$} & $\mathrm{n}$ & 22 & 21 & 23 & & \\
\hline & anti-HBs titer ( 园 $\pm S D)$ & $4.89 \pm 0.59(\mathrm{a})$ & $3.32 \pm 1.21(\mathrm{~b})$ & $2.56 \pm 0.85(\mathrm{c})$ & 37.848 & $<0.001$ \\
\hline
\end{tabular}

anti-HBs unit: $\log 10 \mathrm{mIU} / \mathrm{mL}, p(\mathrm{AB})=0.004, p(\mathrm{BC})=0.238, p(\mathrm{AC})<0.001, p(\mathrm{ab})<0.001, p(\mathrm{bc})=0.008, p(\mathrm{ac})<0.001$.

Table 3. Factors related to high-response to HepB Vac among mice 


\begin{tabular}{|c|c|c|c|c|c|c|}
\hline \multirow[t]{2}{*}{ Item } & \multirow[t]{2}{*}{$\mathrm{n}$} & \multirow{2}{*}{$\frac{\text { anti-HBs }>1000 \mathrm{mIU} / \mathrm{mL}}{\mathrm{n}(\%)}$} & \multicolumn{2}{|c|}{ Univariate analysis } & \multicolumn{2}{|c|}{ Multivariate analysis } \\
\hline & & & $\mathrm{RR}$ value $(95 \% \mathrm{CI})$ & $p$ value & $\mathrm{RR}$ value $(95 \% \mathrm{CI})$ & $p$ value \\
\hline Sex & & & $1.209(0.747,1.956)$ & 0.439 & & \\
\hline Male & 139 & $75(54.0)$ & & & & \\
\hline Female & 128 & $63(49.2)$ & & & & \\
\hline HBIG dose & & & & $<0.001$ & & $<0.001$ \\
\hline $0 \mathrm{IU}(1)$ & 89 & $73(82.0)$ & $9.614(4.757,19.429)$ & $<0.001$ & $20.375(8.414,49.341)$ & $<0.001$ \\
\hline $25 \mathrm{IU}(2)$ & 91 & $37(40.7)$ & $1.444(0.781,2.668)$ & 0.241 & $1.509(0.734,3.102)$ & 0.263 \\
\hline 50 IU (3) & 87 & $28(32.2)$ & & & & \\
\hline HepB Vac dose & & & $3.622(2.186,6.003)$ & $<0.001$ & 6.707 (3.435, 13.098) & $<0.001$ \\
\hline $5 \mu \mathrm{g}$ & 134 & $90(67.2)$ & & & & \\
\hline $2 \mu \mathrm{g}$ & 133 & $48(36.1)$ & & & & \\
\hline Route of HepB Vac injection & & & $3.400(2.056,5.622)$ & $<0.001$ & $6.727(3.428,13.201)$ & $<0.001$ \\
\hline intramuscular & 132 & $88(66.7)$ & & & & \\
\hline hypodermic & 135 & $50(37.0)$ & & & & \\
\hline
\end{tabular}

\section{Supplemental Information Note}

An additional file shows the design of the study in more detail [see Supplemental data].

Supplementary table 1. Immunization scheme of group A. $M$, intramuscular injection; $\mathrm{H}$, hypodermic injection. HBIG was administrated by intraperitoneal injection

Supplementary table2. Immunization scheme of group B. M, intramuscular injection; $H$, hypodermic injection. HBIG was administrated by intraperitoneal injection

\section{Supplementary Files}

This is a list of supplementary files associated with this preprint. Click to download.

- Supplementaldata.docx 